\title{
Jha die Ue[ex!
}

Q18 id baran ging, bas Material zu meiner

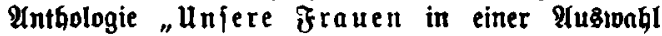
aus igren Difturgen" zu fammeln, Iernte if unter

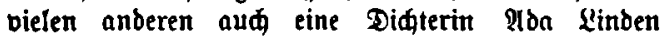
tennen, beren erzählende Poefien einen bejonderz guinftigen Cinbrud auf mid maditen. Geute weißs iđ), bas mein Urteil von gewidfigeren शiännern ge= teilt wurbe, benn fein geringerer als Emanuel Beibel

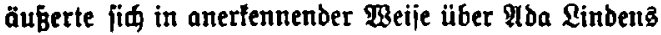
Bebidte, unb Emil Mitterbaus unterftügte bie auj. einem einfamen Dorfe lebende Diøterin in igren litterarifकen Beftrebungen.

Ilba Linben, eigentlic) Luife Förfter, ift bie Tohter einez Grubenfleigers aus Blüđżthal in ber preupiffen Rheinlrobing und wurbe dort am 1. Ot= tober 1847 geborent. Das balb vaterlos geroorbene Mäbden bejumte bie Sdule bes Rađbardorfes und fand bajelbit in bem Pfarrer ber Gemeinde, Serrn 5. Dörrien, einen giltigen Bejajüzer und Berater, ber unjere Diditerin unterridjtete, io $\delta a b^{\circ}$ es thr ipäter möglid murbe, bie Lehrerinnenprüfung zu be= ftehen und eine Stüßze ber Shrigen zu werben.

巨aon in ber findbeit fang fie auf bem weiten

und einjamen 2 ege in bie Sdjule felbitgebidtete 
Sieber vor fĭd hin, und fpäter, wenn Blemüt unb Bhantafie zur poetifien Silukerung brängten, fđrieb fie ibre Berje auf und trat bann unter bem ifion genannten $\mathfrak{B i e u b o n y m}$ an bie Sijentlidteit. $\mathfrak{w}_{08}$ fo im Qauje ber Jabre an poetifaen frühten ent= itanb, baz̧ foll teilweife, in biejem Büdlein ge= jammelt, an bie Dffentlidleit treten und podt an bie Thüren jener familien, wo ber Sinn für baz

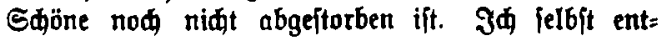

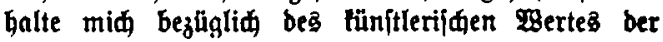
Bebidte jeder Bemertung; die firtiti wird integ emiten Pimtes walten, und bas \$ublithm wirb burd) bie Plufnahme antworten, bie es bem Bǘlein zuteil twerden läst.

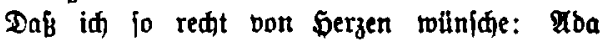
Lindens Roejten mögen in ber beutiđen zamilie, injonberfeit in ifrer engeren Seimat ein gern ge= fehener Gait merden, bas will iø faon aus bem Brnunbe nidit unterbrilfen, weil $e$ ş ber einjamen Didterin, bie burd) ein Serzleiben gezinungen wurbe,

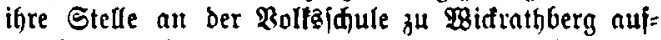

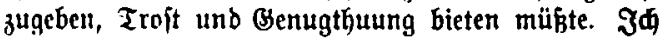

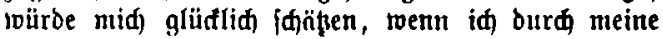
bejđeibenen 280 rte bazu beitragen tönnte, ber leiden= ben Did)terin nuळ zur Pnerfennung zu verfelfen.

Brȩ́burg, im Epätherbft 1895.

$$
\text { Brof. Earl meiß-2atrattentbal. }
$$

